\title{
Psychological symptoms during and after Austrian first lockdown in individuals with bipolar disorder? A follow-up control-group investigation
}

Nina Dalkner', Jolana Wagner-Skace ${ }^{2 *}$, Michaela Ratzenhofer ${ }^{1}$, Frederike Fellendorf ${ }^{1}$, Melanie Lenger ${ }^{1}$, Alexander Maget ${ }^{1}$, Adelina Tmava-Berisha ${ }^{1}$, René Pilz ${ }^{1}$, Robert Queissner ${ }^{1}$, Carlo Hamm', Susanne Bengesser ${ }^{1}$, Martina Platzer ${ }^{1}$, Armin Birner $^{1}$ and Eva Reininghaus ${ }^{1}$

\begin{abstract}
Background: The coronavirus disease (COVID-19) pandemic, a global health crisis, has resulted in widespread socioeconomic restrictions including lockdown, social distancing, and self-isolation. To date, little is known about the psychological impact of the COVID-19 pandemic and lockdown on patients with bipolar disorder as a particularly vulnerable group.

Methods: An online survey was conducted in Austria at two points of measurement (T1 April 2020 during the first lockdown vs. T2 May 2020 at post-lockdown). The sample comprises 20 patients with bipolar disorder (mean age $=49.4 \pm 15.6$ years) and 20 healthy controls (mean age $=32.7 \pm 9.6$ years). $\mathrm{A} 2 \times 2$ factorial design to compare two time points (T1 vs. T2) and two groups (patients vs. healthy controls) was used. Main outcome measures included the Brief Symptom Inventory-18 (BSI-18) and a (non-validated and non-standardized) assessment to determine COVID-19 fears and emotional distress due to social distancing. Multiple linear regression analyses were used to assess the longitudinal association of COVID-19 fears/emotional distress due to social distancing during lockdown (T1) and psychological symptoms after lockdown (T2).

Results: At T1, results demonstrated higher scores in BSI-18 subscales depression, anxiety and global severity index as well as emotional distress due to social distancing in bipolar patients compared to controls. There was a significant time $x$ group interaction in the BSI-18 subscale somatization showing a decreasing trend in patients with BD compared to controls. No time effects in BSI-18 subscales or COVID-19 fears/emotional distress due to social distancing were observed. Regression analyses showed that COVID-19 fears during lockdown predicted somatization, only in patients.
\end{abstract}

Conclusions: There was a connection between the lockdown measures and somatization symptoms observed in patients. When the first steps of easing the social restrictions in May 2020 took place, somatization decreased only in the bipolar compared to the control group. Higher COVID-19 fears during lockdown predicted later symptoms at post-lockdown. Long-term impacts of the COVID-19 pandemic need further investigations to improve current

\footnotetext{
*Correspondence: jolana.wagner-skacel@medunigraz.at

${ }^{2}$ Department of Medical Psychology and Psychotherapy, Medical

University of Graz, Auenbruggerplatz 3, 8036 Graz, Austria

Full list of author information is available at the end of the article
} in this article are included in the article's Creative Commons licence, unless indicated otherwise in a credit line to the material. If material is not included in the article's Creative Commons licence and your intended use is not permitted by statutory regulation or exceeds the permitted use, you will need to obtain permission directly from the copyright holder. To view a copy of this licence, visit http://creativeco mmons.org/licenses/by/4.0/. 
therapeutic approaches and prevent fears and distress during lockdown in individuals with bipolar disorder in times of crisis.

Keywords: Bipolar disorder, COVID-19, Lockdown, Global symptom load, Somatization, Depression, Anxiety

\section{Introduction}

The severe acute respiratory syndrome coronavirus-2 (SARS-CoV-2), which can cause the novel coronavirus disease (COVID-19) and its consequences (e.g., quarantine, lockdown, and social distancing), represent a global health crisis, and the whole world has experienced a state of emergency (Guan et al. 2020. To date, in October 2020, the ongoing COVID-19 pandemic has infected more than 33 million people and led to more than one million deaths globally (Johns Hopkins University 2020). The COVID-19 pandemic is leading directly or indirectly to extraordinary challenges for mental health services (Fatke et al. 2020; Rajkumar 2020). Insecurity, confusion, emotional isolation, and stigma may affect mental health and well-being (Pfefferbaum and North 2020). Psychological stress symptoms (including depression, somatization, insomnia, and anxiety) can be consequences of such an extraordinary situation, including feelings of threat and uncertainty (Lieberman et al. 2020; Pérez-Fuentes et al. 2020). The effects may lead to severe emotional reactions, unhealthy behaviours, or noncompliance with public health directives (Pfefferbaum and North 2020). Furthermore, emotional responses to the COVID-19 pandemic can result in relapse or worsening of an already existing psychiatric disorder because of high susceptibility to stress compared with the general population (Pérez-Fuentes et al. 2020).

$\mathrm{BD}$ is a recurrent chronic psychiatric disorder characterized by fluctuations in mood state and energy (Vieta et al. 2016), and can cause people to have a more reactive response to stress when compared to healthy controls. Studies show that individuals with BD exhibit a high risk of developing severe affective episodes during periods with high chronic stress (Bender and Alloy 2011; Malkoff-Schwartz et al. 2000; Weiss et al. 2015). The vulnerability-stress model postulates a neurobiological, polygenic genetic predisposition in concatenation with chronic stress and acute triggers (e.g., critical life events, disruption of the sleep-wake rhythm), which determine the course of psychiatric disorders by gene-environment interactions (e.g., infections and inflammation) mediated by epigenetic modifications, gene expression changes, and other cellular mechanisms (Bengesser and Reininghaus 2018; Brietzke et al. 2012; Esterwood and Saeed 2020). The COVID-19 crisis may be a life event in itself. In this paper, we are especially interested whether patients with BD are more susceptible to psychological symptoms in an extreme environmental situation, as it was the case during lockdown.

Since the outbreak of the COVID-19 pandemic, numerous studies evaluating psychiatric symptoms in individuals with severe mental illness including samples with BD have been published (Chang et al. 2020; Costa et al. 2020; Frank et al. 2020; Hao et al. 2020; Iasevoli et al. 2020; Pan et al. 2020; Riblet et al. 2020; Solé et al. 2021; Zou et al. 2020). Rates of high perceived stress severity, anxiety, and severe depressive symptoms were significantly higher in psychiatric patients compared with controls (Frank et al. 2020; Iasevoli et al. 2020, Solé et al. 2021). In addition, patients reported on sleeping problems (Frank et al. 2020) and fatigue (Zou et al. 2020). A very recent study from Australia, focusing on psychosocial distress in patients with mood disorders, highlighted the maladaptive situational and lifestyle changes during the COVID-19 pandemic of this patient group. In particular, patients with $\mathrm{BD}$ reported high stress levels and men with $\mathrm{BD}$ had even higher levels of depression than women with $\mathrm{BD}$ in this study. Respondents with BD were more concerned about financial issues associated with COVID-19 compared to those with depressive disorder and those with no mental disorder. However, mood disorders in this study were self-reported (Van Rheenen et al. 2020). A further reason for psychological stress symptoms caused by the COVID19 pandemic might be social distancing rules that were promulgated and enforced by many governments to prevent an uncontrolled spread of SARS-CoV-2.

Lockdown and social distancing (also known as physical distancing) included in infection control actions is intended to slow the spread of disease by minimizing close contact between individuals. However, lockdown, quarantine, and social distancing procedures may lead to loss of personal freedom, uncertainty, fear of the future, and financial well-being, and they also may contribute strongly to widespread emotional distress and mental health problems (Pfefferbaum and North 2020; Semo and Frissa 2020; Zandifar and Badrfam 2020). An Italian study by Rossi et al. (2020) identified associations of lockdown measures with high rates of depression, anxiety, insomnia, perceived stress symptoms and adjustment disorder symptoms in the general population. Brooks et al. (2020) reviewed the psychological impact of quarantine and found negative psychological effects, including post-traumatic stress symptoms, confusion, and anger. Stressors included longer quarantine duration, 
infection fears, frustration, boredom, inadequate supplies, inadequate information, financial loss, and stigma. Accordingly, Tull et al. (2020) found that being under a stay-at-home order was associated with greater health anxiety, financial worry, and loneliness in healthy adults.

In psychiatric samples, lockdown measures including temporary shutdown of medical and mental health treatment and the disrupted rhythm of a healthy life, such as reduced opportunities to exercise, experience sunlight exposure, and participate in meaningful activities, could pose a special risk or relapse during the pandemic (Muruganandam et al. 2020; Youngstrom et al. 2020). Hao et al. (2020) confirmed that patients with psychiatric disorders experienced more psychiatric symptoms during the COVID-19 pandemic. They highlighted the severity of negative psychological impact on psychiatric patients during strict lockdown measures. An Italian study by Carmassi et al. (2020), surveying 100 patients with BD in April 2020, found more post-traumatic stress symptoms, more anxiety, and depressive symptoms during the period of national lockdown and ongoing social distancing measures. Post-traumatic stress symptoms were related to work and financial difficulties. Interestingly, acute manic symptoms seemed to be protective in this study. A Spanish study by González-Blanco et al. (2020) evaluated depression, anxiety, and stress symptoms as early responses to the pandemic and found that patients with severe mental disorders (bipolar and psychotic disorders) reacted to the lockdown restrictions with higher anxiety levels compared to healthy controls. Solé et al. (2021) stated that lockdown had a higher psychological impact in psychiatric patients vs. controls and that psychiatric patients used less adaptive copings strategies to face the lockdown. Moreover, suicidality case reports as well as increased suicidality rates related to the COVID-19 pandemic because of fear and xenophobia have already been reported (Dsouza et al. 2020; Mamun and Griffiths 2020; Sher 2020). Consequently, several adjustment strategies to prevent psychological stress and suicide attempts during the COVID-19 pandemic have already been published (Ho et al. 2020; Klomek 2020; Wu et al. 2020). Interestingly, there are also few studies showing decreased psychiatric symptoms due to the pandemic. A longitudinal study by Orhan et al. (2020) observed less psychiatric symptoms in older patients with BD (age > 50 years) during the course of the COVID19 pandemic than at baseline. Psychiatric symptoms were associated with loneliness, not having children, more feelings of loneliness, lower mastery, passive coping style and neuroticism.

Yao et al. (2020) pointed out that individuals with psychiatric disorders are generally more susceptible to infections for multiple reasons including cognitive impairment and little awareness of risk, more comorbidities and more barriers in accessing timely health services. Accordingly, it is suggested that patients with BD exhibit more serious COVID-19-related symptoms (Stefana et al. 2020) and that they are at increased infection risks due higher prevalence of obesity, cardiovascular disease, diabetes mellitus, and obstructive pulmonary disease (Staudt et al. 2019; McIntyre et al. 2007; Vancampfort et al. 2013; Vancampfort et al. 2016; Zareifopoulos et al. 2018). There are already recommendations for patients with $\mathrm{BD}$ for the time of the COVID-19 pandemic to decrease the vulnerability, such as proactively improving social connections, prioritizing self-care, and learning to use mobile and telehealth effectively (Stefana et al. 2020; Youngstrom et al. 2020). However, more multidisciplinary research on COVID-19 effects on severe symptoms of BD is needed to accomplish a consequent establishment of prevention strategies for psychiatric COVID-19 consequences (Courtet et al 2020; Holmes et al. 2020).

This study aimed at investigating the psychosocial strain of Austrian patients with BD during the COVID19 pandemic at two time points (April 2020 vs. May 2020) via an online survey. Austria was in the first lockdown from March 15 to the end of April 2020, and the survey was conducted twice: April 9-April 28, 2020 (T1) and the second time from May 5-June 4, 2020 (T2). Individual differences in the emotional response to the pandemic and effects of governmental restrictions including social distancing and lockdown might be critical for the comprehension of psychological pandemic effects and the construction of new management and treatment models. Thus, we conducted a single-institution prospective analysis to address the following research questions:

1. Do patients with BD and healthy controls differ in a) global severity index, anxiety, depression, and somatization in the course of the pandemic (during and post-lockdown) and in b) COVID-19 fears and emotional distress due to social distancing?

2. Do COVID-19 fears and emotional distress due to social distancing during lockdown (T1) can predict psychological symptoms post-lockdown (T2) in patients vs. healthy controls?

We hypothesized that psychological symptoms in individuals with $\mathrm{BD}$ depend on lockdown measures and that patients with BD may report more psychological stress symptoms (anxiety, depression, somatization) during the first Austrian lockdown (vs. post-lockdown) in comparison to a healthy control group. In addition, we assumed that COVID-19 fears and emotional response to social distancing will be related to psychological symptoms, resulting in higher effects in patients. 


\section{Materials and methods Study design}

Data collection (T1) via online survey began on April 9 and ended on April 28, 2020. Between May 5 and June 4,2020 , the survey was open for answering for a second time (T2) for the same participants. The first survey in April was during the first total lockdown, starting at March 16, 2020 with governmental measures to limit the spread of COVID-19 in Austria. At this time all nonessential shops, schools, nurseries, and leisure premises were closed, all events were cancelled, and home-office rather than in-office work was recommended (except for key workers) or workers were put on furlough. Essential venues were only accessible when wearing face masks and keeping a distance of at least one meter. Furthermore, the public was advised to stay at home and to limit all real-life contacts except for people sharing the same household. Travel to and from Austria was heavily restricted by the government. Up to April 9, 13,120 cases were confirmed in Austria, of which 7585 people were actively infected and 295 people had died in connection with COVID-19; by April 28, 15,357 cases were confirmed, of which 2208 were actively infected and 569 had died (Nussmayr 2020).

The follow-up survey at T2 was conducted when restrictions where loosened, including permission for events with up to 10 people, and all shops, leisure venues, and hairdressers were allowed to open again. In the middle of May, number-restricted reopening of schools, restaurants, and places of worship took place. Wearing a face mask inside and keeping distance was still mandatory, and travel restrictions remained. At the end of May, events up to 100 people were allowed again. Up to May 5, 15,650 cases were confirmed in Austria, of which 1,582 people were actively infected and 606 people had died in connection with COVID-19; by June 4, 16,805 cases were confirmed, of which 418 were actively infected and 670 had died in Austria (Nussmayr 2020). An overview of the governmental measures in Austria at both time points of this study is given in Fig. 1.

\section{Participants}

This study surveyed former participants of the BIPLONG study, and all patients were diagnosed earlier with the Structured Clinical Interview for DSM-IV (SCID-I) and treated at the outpatient center for BD at the Medical University of Graz, Department of Psychiatry and Psychotherapeutic Medicine. Participants answered the questionnaires pseudo-anonymously using a participant code of former studies (see our recent report on the BIPLONG study by Dalkner et al. 2020). Inclusion criteria included voluntary participation (informed consent), German native speakers, age above 18 years, and e-mail access. We surveyed 38 patients with BD and 39 healthy controls at $\mathrm{T} 1$ and 23 patients with BD and 22 healthy controls at $\mathrm{T} 2$. Total data sets at both time points including all relevant variables were available from 20 participants with BD vs. 20 healthy controls. The healthy controls included were also former study participants and had no psychiatric disease or positive family history of a psychiatric disease. This was screened in the BIPLONG study and again in the COVID-19 survey. This study was conducted in accordance with the Declaration

\begin{tabular}{|c|c|c|c|c|c|c|c|c|}
\hline & \multicolumn{8}{|c|}{ Covid-19 governmental measures in Austria } \\
\hline & Survey Start & Exit regulations & Behaviour guidelines & Travel regulations & Event regulations & $\begin{array}{c}\text { Educational } \\
\text { institutions }\end{array}$ & Service sector & Survey End \\
\hline $\mathbf{T 1}$ & 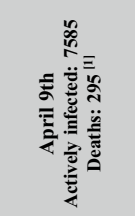 & $\begin{array}{l}\text { People are required to } \\
\text { stay at home and only } \\
\text { leave the house for } \\
\text { essential reasons: } \\
\text { 1) professional work 2) } \\
\text { essential errands } \\
\text { 3) to help others } \\
\text { 4) physical activity }\end{array}$ & $\begin{array}{l}\text { Keeping distance and } \\
\text { wearing face masks in } \\
\text { shops, offices, public } \\
\text { transport is mandatory. }\end{array}$ & $\begin{array}{l}\text { Only essential travel } \\
\text { (e.g. for business that } \\
\text { cannot be delayed) is } \\
\text { permitted. } \\
\text { Entry regulations are in } \\
\text { effect. }\end{array}$ & $\begin{array}{l}\text { All events such as } \\
\text { concerts, plays, } \\
\text { exhibitions etc. are } \\
\text { prohibited }\end{array}$ & $\begin{array}{l}\text { Nurseries, } \\
\text { kindergartens, schools, } \\
\text { universities are closed. }\end{array}$ & $\begin{array}{l}\text { Restaurants/bars, health } \\
\text { and rehabilitation } \\
\text { resorts, sports areas, } \\
\text { culture and leisure } \\
\text { facilities are closed. } \\
\text { Only essential shops are } \\
\text { open. }\end{array}$ & 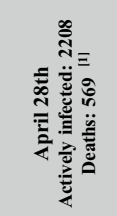 \\
\hline $\mathbf{T} 2$ & 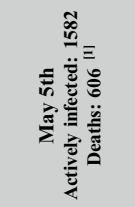 & $\begin{array}{l}\text { Restrictions to leave the } \\
\text { house are lifted. }\end{array}$ & $\begin{array}{l}\text { Order to keep } 1.5 \text { metre } \\
\text { distance and wearing } \\
\text { face masks in shops, } \\
\text { offices, public transport. }\end{array}$ & $\begin{array}{l}\text { Travel regulations } \\
\text { remain. }\end{array}$ & $\begin{array}{l}\text { May 1st: Events with } \\
\text { participants up to } 10 \\
\text { people and funerals up } \\
\text { to } 30 \text { people are } \\
\text { allowed. May } 15 \text { th: } \\
\text { Weddings and funerals } \\
\text { of up to } 100 \text { people are } \\
\text { allowed. }\end{array}$ & $\begin{array}{l}\text { May 15th: Reopening of } \\
\text { Nurseries, } \\
\text { kindergartens, schools, } \\
\text { universities. }\end{array}$ & $\begin{array}{l}\text { May 15th: Number } \\
\text { restricted reopening of } \\
\text { f restaurants/bars, health } \\
\text { and rehabilitation } \\
\text { resorts, sports areas, } \\
\text { culture and leisure } \\
\text { facilities, shops, } \\
\text { theatres, etc. }\end{array}$ & 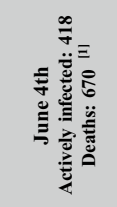 \\
\hline & & & & ${ }^{[1]}$ Nussmayr, 202 & & & & \\
\hline
\end{tabular}


of Helsinki and was approved by the Ethics Committee of the Medical University Graz (EK-number: 25-335 ex 12/13). Participants could withdraw from the survey at any moment without providing any justification.

\section{Psychological inventories}

The web-based survey, in German, was accessible online using the survey tool LimeSurvey; it solicited answers to the following question topics:

Global symptom load was assessed using the German version of the Brief Symptom Inventory-18 (BSI-18; Franke et al. 2017) by Derogatis and Fitzpatrick (2004), a short version of the Symptom-Checklist-90 Revised (Derogatis and Unger 2010). The BSI-18 comprises 18 items assessing psychological distress in the last 7 days on three subscales (depression, anxiety, and somatization). The global severity index (GSI) is a global measure of psychological distress. The BSI-18 employs a 5-point rating form ranging from 1 ("absolutely not") to 5 ("very strong"). The subscales (total value of each scale is 24) show an internal consistency with a Cronbach's alpha of $\alpha=0.82$ for Somatization, $\alpha=0.87$ for Depression, $\alpha=0.84$ for Anxiety and $\alpha=0.93$ for GSI. (Derogatis and Fitzpatrick 2004).

The Beck Depression Inventory (BDI-2) was used as a self-evaluation report to assess the severity of depressive symptoms, with 21 items and a 4-point Likert scoring system. The total score ranges from 0 to 63 points. According to the manual, a score below 18 indicates a lack of clinical depression. The scale has been shown to demonstrate an internal consistency with a Cronbach's alpha of $\alpha \geq 0.84$ and a reliability of $r \geq 0.75$ (Kühner et al. 2007).

The Altman Self-Rating Mania Scale (ASRM) by Altman et al. (1997) is a five-item scale for assessing mood, self-confidence, sleep disturbances, speech, and activity level during 1 week. Each question can be rated with 0 to 4 points, and a total score above five indicates mania.

Demographic information included personal data (sex, age, education, relationship status), information about the living situation (inhabitants in home town, people in household, children), engagement in activities and hobbies, the presence of a daily structure, adherence to medication (changes in current medication) and governmental measures, and contact with a mental health professional (psychiatrist, psychologist, psychotherapist).

A COVID-19 assessment was developed by the Department of Psychiatry and Psychotherapeutic Medicine at the Medical University of Graz assessing COVID-19 fears, as follows $(0=$ no fears, $10=$ extremely high fear):

- On a scale from 0 to 10, how strongly do you rate your concerns and fears about the coronavirus?
- On a scale from 0 to 10, how strongly do you rate your fear of contracting the coronavirus?

- On a scale from 0 to 10, how strongly do you rate your fear of infecting others with the coronavirus?

The three items showed a highly significant intercorrelation (all $p<0.01$ ), and a mean index for COVID-19 fears was created, showing a Cronbach's alpha of $\alpha=0.81$ at T1 and $\alpha=0.82$ at $\mathrm{T} 2$.

Emotional distress due to social distancing was assessed by the following five items on a 6-point rating scale $(0=$ not at all, $4=$ full commitment):

- On a scale from 0 to 4 , social distancing makes me feel lonely/bored/frustrated/hopeless/anxious.

Out of these significantly intercorrelated items (all $p<$ .01), a mean index for "Emotional distress due to social distancing" was created, showing a Cronbach's alpha of $\alpha$ $=.90$ at $\mathrm{T} 1$ and $\alpha=.86$ at $\mathrm{T} 2$.

\section{Statistical analyses}

A $2 \times 2$ factorial design to compare two time points (T1 vs. T2) $\times 2$ groups (patients with $\mathrm{BD}$ vs. healthy controls) was used. Consequently, repeated measures ANCOVAs (controlling for age, sex, education, and employment) for analyzing global symptom load and subscales of the BSI-18 from same subjects at both time points (combining data from April vs. May) were calculated. For analyses of variance, effect sizes are presented as Cohen's partial eta-squared $\left(\eta^{2}\right)$. Paired $t$-tests were post-hoc computed to demonstrate changes in psychological scales from $\mathrm{T} 1$ to T2 within one group. Multiple linear regression analyses controlling for age, sex, education, and employment were applied to assess whether COVID-19 fears as well as emotional distress due to social distancing during lockdown (T1) as independent variables can predict psychological symptoms (somatization, depression, anxiety, GSI) after lockdown (T2); multiple regression models were compared between groups. Basic statistical requirements to run multiple regression analyses were met and preliminary analyses were conducted to check relevant assumptions of regression analysis including linearity, normality, absence of multicollinearity, and homoscedasticity. Cohen's $f 2$ were calculated as a measure of effect size interpreted according to Cohen (1988) as small $(f 2=0.02)$, medium $(f 2=0.15)$, and big effects $(f 2=0.35)$. Differences in clinical data between patients with $\mathrm{BD}$ and healthy controls at one time point were calculated with chi-square tests (for nominal) and the Freeman-Halton Fisher's exact test, when the expected cell size was $<5$, and $t$-tests (for metric data) and Mann-Whitney $U$ tests (for nonparametric data). The overall significance was set 
at 0.05 and all analyses were performed using the Statistical Package for Social Sciences (SPSS version 25.0, IBM).

\section{Results}

\section{Sample description}

The sociodemographic characteristics of participants are shown in Table 1 . Fifty percent of the 20 patients and $75.0 \%$ of the 20 controls were females. The mean age of the participants was $49.35 \pm 15.55$ years in the patient group and $32.65 \pm 9.58$ years in the control group. Patients were more frequently retired $\left(x^{2}(6)=22.01\right.$, $p<0.001)$ and had a lower educational level $\left(\chi^{2}(5)=10.28\right.$, $p=0.050$; see Table 1 ). Of all participants, no one had tested positive for COVID-19, no one lived together with someone who tested positive for COVID-19, and no one was put under quarantine (because of contact with positive COVID-19 cases) at the time of testing or before. Patients suffered significantly more from cardiovascular

Table 1 Demographic data

\begin{tabular}{|c|c|c|c|}
\hline & $\mathrm{BD}(n=20)$ & Controls $(n=20)$ & Statistics \\
\hline \multicolumn{4}{|l|}{ Sex } \\
\hline Male $(N)$ & 10 & 5 & \\
\hline Female $(N)$ & 10 & 15 & $x^{2}(1)=2.67, p=0.102$ \\
\hline \multicolumn{4}{|l|}{ Age } \\
\hline Years $(M, S D)$ & $49.35(15.55)$ & 32.65 (9.58) & $t(38)=4.09, p<0.001$ \\
\hline \multicolumn{4}{|l|}{ Highest education } \\
\hline Compulsory education $(N)$ & 2 & 0 & $x^{2}(5)=10.28, p=0.050^{a}$ \\
\hline Apprenticeship $(N)$ & 7 & 1 & \\
\hline A-Levels $(N)$ & 5 & 4 & \\
\hline University Bachelor's Degree ( $N$ ) & 1 & 4 & \\
\hline University Master's Degree $(N)$ & 4 & 7 & \\
\hline University Doctorate $(N)$ & 1 & 4 & \\
\hline \multicolumn{4}{|l|}{ Marital status } \\
\hline Married, in relationship $(N)$ & 12 & 12 & $x^{2}(3)=5.33, p=0.149^{a}$ \\
\hline Single $(N)$ & 4 & 8 & \\
\hline Divorced/Widowed ( $N$ ) & 3 & 0 & \\
\hline \multicolumn{4}{|l|}{ Employment } \\
\hline Unemployed, before the pandemic & 1 & 0 & $x^{2}(6)=22.01, p<0.001^{a}$ \\
\hline Unemployed, due to the pandemic & 1 & 0 & \\
\hline Short-time work & 2 & 1 & \\
\hline Retired/rehabilitation & 10 & 0 & \\
\hline Student & 1 & 3 & \\
\hline Home office & 5 & 10 & \\
\hline Employed & 0 & 6 & \\
\hline \multicolumn{4}{|l|}{ Living situation } \\
\hline Alone $(N)$ & 5 & 3 & $x^{2}(6)=4.99, p=0.605^{\mathrm{a}}$ \\
\hline With partner $(N)$ & 5 & 7 & \\
\hline With partner and children $(N)$ & 5 & 3 & \\
\hline With child/children $(N)$ & 0 & 1 & \\
\hline In a shared residence $(N)$ & 1 & 2 & \\
\hline With parents $(N)$ & 2 & 4 & \\
\hline In a multi-generation household $(N)$ & 2 & 0 & \\
\hline \multicolumn{4}{|l|}{ Inhabitants town of residence } \\
\hline$<1000$ Inhabitants $(N)$ & 3 & 1 & $x^{2}(3)=6.27, p=0.108$ \\
\hline 1000-4999 Inhabitants $(N)$ & 6 & 1 & \\
\hline 5000-9999 Inhabitants $(N)$ & 2 & 3 & \\
\hline$\geq 10.000$ Inhabitants $(N)$ & 9 & 15 & \\
\hline
\end{tabular}

$B D$ bipolar disorder

a Fisher's exact test 
disease than controls $\left(\chi^{2}(1)=5.71, p=0.017\right)$. No differences between patients and controls were found in history of diabetes $\left(\chi^{2}(1)=3.24, p=0.231\right)$, obstructive pulmonary disease $\left(\chi^{2}(1)=2.11, p=0.487\right)$, and hypertension $\left(\chi^{2}(1)=2.11, p=0.487\right.$; see Table 2). Of the patients, $25 \%$ reported using online counseling or online therapy during the pandemic; however, $30 \%$ stated not having any contact with their treating psychiatrist or psychologist during the lockdown. In this study, no sex differences in COVID-19 fears, emotional distress due to social distancing, or psychological symptoms were observed (all $p<0.05$ ). The clinical data (somatic comorbidities, medication, and clinical self-ratings with BDI-2 and ASRM) are presented in Table 2.

In April, 90\% (vs. 95\% in May) of the patients reported taking their medication regularly, and as prescribed without arbitrary change of dosage. In addition, $45 \%(n=9)$ of patients reported subjective negative effects of the COVID-19 pandemic on their mental well-being (vs. $40 \%$ of controls; $\left.\chi^{2}(1)=1.63, p=0.202\right)$, and $25 \%(\mathrm{n}=5)$ (vs. $20 \%$ of controls; $X^{2}(1)=0.224, p=0.638$ ) reported positive effects; the rest reported no effect. For a negative valuation of lockdown, patients listed amongst others little social contacts, loss of daily structure, and suspension of psychotherapy. Positive ratings of lockdown comprised amongst others more time for oneself.

\section{Psychological symptoms at the peak of the lockdown in April 2020 vs. post-lockdown in may 2020}

Patients with BD differed from healthy controls in the median GSI decrease from $\mathrm{T} 1$ to $\mathrm{T} 2\left(\mathrm{X}^{2}(2)=6.63\right.$, $p=0.036$ ). Fourteen patients (vs. six healthy controls) showed a decrease and five patients (vs. eight controls) showed an increase in GSI from T1 to T2, with a minimum of -16 and a maximum of +9 points in the BD group and -4 to +10 points in healthy controls. The other participants showed no difference in GSI from T1 to T2. Figure 2 displays the median change from $\mathrm{T} 1$ to $\mathrm{T} 2$ in GSI.

\section{Somatization}

For the subscale somatization, a two-tailed repeated measures ANCOVA (controlled for age, sex, education, and employment) showed no main effect time point $\left(F_{(1,}\right.$ 34) $\left.=1.20, p=0.280, \eta^{2}=0.034\right)$ and no main effect group (at T1) $\left(F_{(1,34)}=2.82, p=0.102, \eta^{2}=0.077\right)$. As shown in Fig. 3, there was a significant interaction between time point (April vs. May) and group (patients vs. controls) in somatization $\left(F_{(1,34)}=5.22, p=0.029, \eta^{2}=0.133\right)$. Post-hoc paired $t$-tests showed a decreasing trend in BD patients $\left(T_{(19)}=1.98, p=0.062\right)$, but no change in somatization in healthy controls $\left(T_{(19)}=-0.72, p=0.481\right)$. The covariables age $\left(\eta^{2}=0.045\right)$, sex $\left(\eta^{2}=0.006\right)$, education $\left(\eta^{2}=0.002\right)$, and employment $\left(\eta^{2}=0.006\right)$ showed no significant effects on somatization (all $p>0.05$ ). The statistical results, means and standard deviations are presented in Table 3.

\section{Depression}

For the subscale depression, there was no main effect time point $\left(F_{(1,34)}=0.21, p=0.651, \eta^{2}=0.006\right)$, but a main effect group $\left(F_{(1,34)}=11.73, p=0.002, \eta^{2}=0.256\right)$

Table 2 Clinical data

\begin{tabular}{|c|c|c|c|}
\hline & $\mathrm{BD}(n=20)$ & Controls $(n=20)$ & Statistics \\
\hline \multicolumn{4}{|l|}{ Mood stabilizers } \\
\hline Lithium & $30 \%$ & - & \\
\hline Atypical antipsychotics & $35 \%$ & - & \\
\hline Anticonvulsants & $10 \%$ & - & \\
\hline Others & $25 \%$ & - & \\
\hline \multicolumn{4}{|l|}{ Somatic comorbidities } \\
\hline Cardiovascular disease & 5 & 0 & $x^{2}(1)=5.71, p=0.017^{a}$ \\
\hline Diabetes mellitus & 3 & 0 & $x^{2}(1)=3.24, p=0.231^{\mathrm{a}}$ \\
\hline Obstructive pulmonary disease & 2 & 0 & $x^{2}(1)=2.11, p=0.487^{a}$ \\
\hline Hypertension & 6 & 2 & $x^{2}(1)=2.50, p=0.114$ \\
\hline \multicolumn{4}{|l|}{ Symptom self-ratings } \\
\hline BDI-2 (M, SD), April & $15.45(10.74)$ & $3.10(2.53)$ & $t(38)=5.00, p<0.001$ \\
\hline BDI-2 (M, SD), May & $12.20(11.69)$ & $2.40(2.21)$ & $t(38)=3.69, p<0.01$ \\
\hline $\operatorname{ASRM}(M, S D)$, April & $0.95(2.28)$ & $0.55(1.19)$ & $t(38)=0.70, p=0.491$ \\
\hline $\operatorname{ASRM}(M, S D)$, May & $1.5(2.19)$ & $0.25(0.55)$ & $t(38)=2.48, p=0.022$ \\
\hline
\end{tabular}

$B D$ bipolar disorder, $B D I-2$ beck depression inventory-2, $A S R M$ Altman self-rating mania scale, $M$ mean, SD standard deviation

${ }^{\text {a }}$ Fisher's exact test 
BSI 18 Global Severity Index

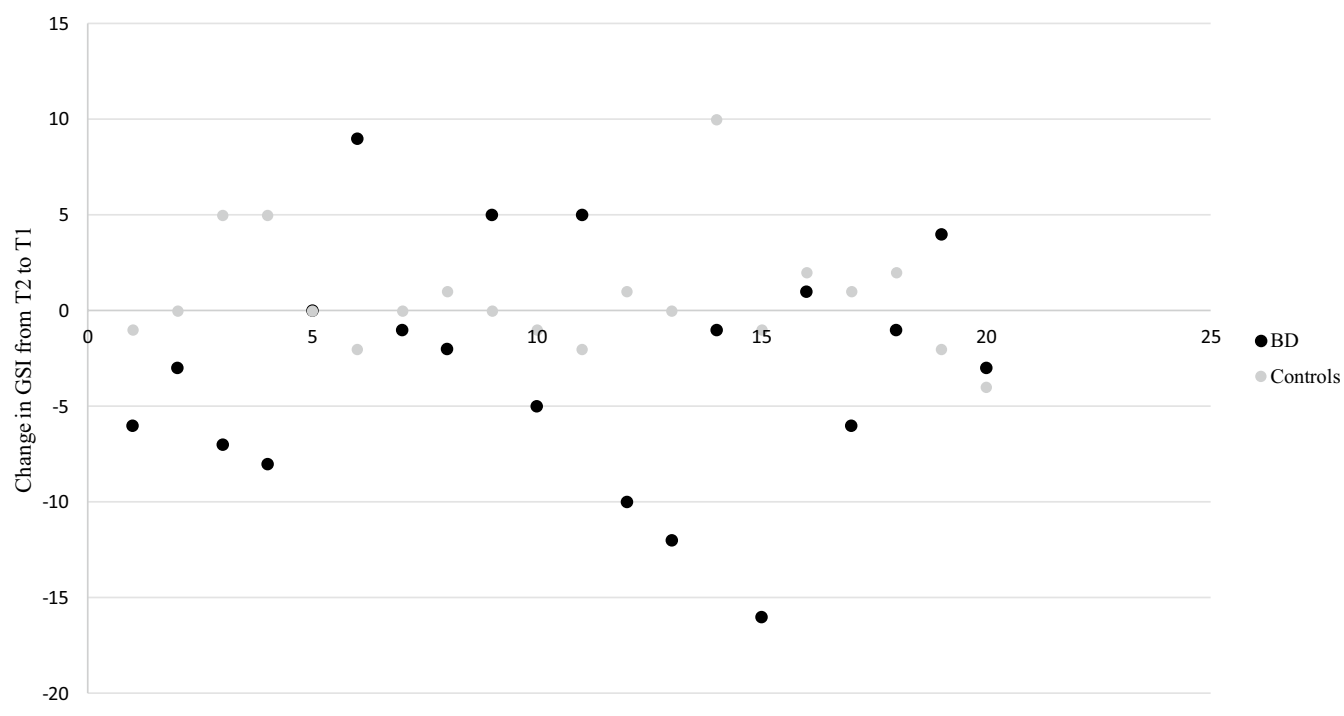

Fig. 2 Median change from T1 to T2 in BSI-18 global severity index(GSI) BD bipolar disorder, GS/ global severity index
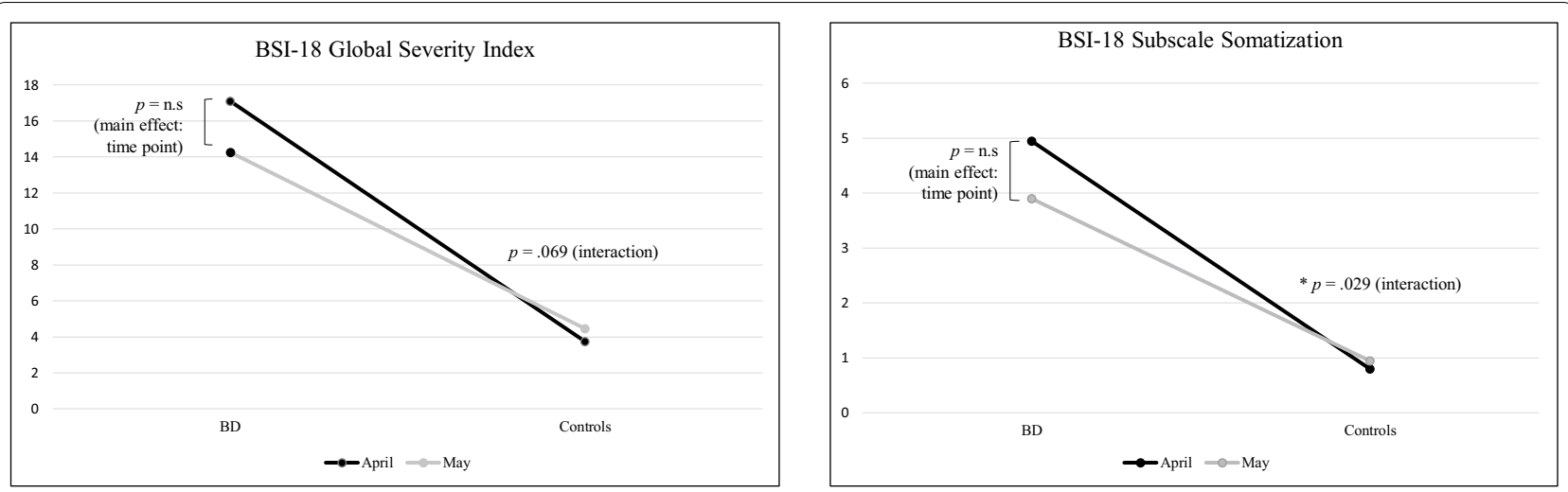

Fig. 3 Main result of the two-tailed repeated measure ANCOVAs for BSI-18 somatization and BSI-18 global severity index (GSI)

Table 3 Results from repeated measures ANCOVAs: Psychological symptoms (BSI-18) in patients with BD vs. healthy controls in April (T1) and May 2020 (T2)

\begin{tabular}{|c|c|c|c|c|c|c|c|c|c|c|}
\hline & \multicolumn{2}{|l|}{$\mathrm{BD}(n=20)$} & \multicolumn{2}{|c|}{ Controls $(n=20)$} & \multicolumn{6}{|c|}{ Statistics } \\
\hline & \multirow{2}{*}{$\begin{array}{l}\mathrm{T} 1 \\
M(S D)\end{array}$} & \multirow{2}{*}{$\begin{array}{l}\mathrm{T} 2 \\
M(S D)\end{array}$} & \multirow{2}{*}{$\begin{array}{l}\mathrm{T} 1 \\
M(S D)\end{array}$} & \multirow{2}{*}{$\begin{array}{l}\text { T2 } \\
M(S D)\end{array}$} & \multicolumn{2}{|c|}{ Group effect } & \multicolumn{2}{|c|}{ Time effect } & \multicolumn{2}{|c|}{$\begin{array}{l}\text { Time } x \text { group } \\
\text { interaction }\end{array}$} \\
\hline & & & & & $F$ & $p$ & $F$ & $p$ & $F$ & $p$ \\
\hline Somatization & $4.95(5.56)$ & $3.90(5.43)$ & $0.80(1.58)$ & $0.95(1.57)$ & 2.82 & 0.102 & 1.2 & 0.28 & 5.22 & 0.029 \\
\hline Depression & $7.15(6.42)$ & $5.50(6.00)$ & $1.55(1.90)$ & $1.80(2.12)$ & 11.73 & 0.002 & 0.21 & 0.651 & 0.38 & 0.544 \\
\hline Anxiety & $5.00(4.46)$ & $4.85(5.37)$ & $1.40(1.19)$ & $1.70(2.13)$ & 9.48 & 0.004 & 1.3 & 0.263 & 1.4 & 0.245 \\
\hline GSI & $17.10(13.83)$ & $14.25(14.15)$ & $3.75(3.42)$ & $4.45(4.55)$ & 10.08 & 0.003 & 0.8 & 0.378 & 3.53 & 0.069 \\
\hline
\end{tabular}

Results from repeated measures ANCOVAs controlling for age, sex, education, and employment

$B D$ bipolar disorder, $B S I-18$ brief symptom inventory-18, GSI global severity index, $M$ mean, $S D$ standard deviation 
showing higher scores in the patients group compared to controls. No interaction time $\mathrm{x}$ group for the BSI-18 subscale depression $\left(F_{(1,34)}=0.376, p=0.544, \eta^{2}=0.011\right)$ was found (see Table 3$)$. The covariables age $\left(\eta^{2}=0.022\right)$, sex $\left(\eta^{2}=0.017\right)$, and education $\left(\eta^{2}=0.073\right)$ showed no significant effects on depression (all $p>0.05$ ). There was a significant time $\mathrm{x}$ employment effect $\left(F_{(1,34)}=5.08\right.$, $p=0.031, \eta^{2}=0.130$ ).

\section{Anxiety}

For the BSI-18 subscale anxiety, there was no main effect time $\left(F_{(1,34)}=1.30, p=0.263, \eta^{2}=0.037\right)$. A significant group effect indicating higher anxiety scores $\left(F_{(1,34)}=9.48, p=0.004, \eta^{2}=0.218\right)$ at $\mathrm{T} 1$ in the patient compared to the control group was found. No interaction effect time $\mathrm{x}$ group in anxiety was found $\left(\left(F_{(1,34)}=1.40\right.\right.$, $p=0.245, \eta^{2}=0.040$; see Table 3$)$. The covariables age $\left(\eta^{2}=0.001\right)$, sex $\left(\eta^{2}=0.108\right)$, education $\left(\eta^{2}=0.003\right)$, and employment $\left(\eta^{2}=0.003\right)$ showed no significant effects on anxiety (all $p>0.05)$.

\section{Global severity index}

In GSI, we observed a decreasing trend from April to May in patients (see Fig. 3), however, the time $\mathrm{x}$ group interaction was not significant $\left(F_{(1,34)}=3.53, p=0.069\right.$, $\eta^{2}=0.094$ ). At $\mathrm{T} 1$, there was a significant group effect indicating higher GSI scores in patients compared with healthy controls $\left(F_{(1,34)}=10.08, p=0.003, \eta^{2}=0.229\right)$. Time $\left(\eta^{2}=0.023\right)$, age $\left(\eta^{2}=0.047\right)$, sex $\left(\eta^{2}=0.001\right)$, education $\left(\eta^{2}=0.021\right)$, and employment $\left(\eta^{2}=0.034\right)$ showed no significant effects on GSI (all $p>0.05$ ). Table 3 shows the means and standard deviations as well as ANCOVA statistics of BSI-18 scales.

\section{COVID-19 fears and emotional distress due to social distancing}

Two-tailed repeated measures ANCOVAs for COVID19 fears and emotional distress due to social distancing showed no significant time effects in COVID-19 fears
$\left(F_{(1,34)}=2.73, p=0.108, \eta^{2}=0.074\right)$ or emotional distress due to social distancing $\left(F_{(1,34)}=0.44, p=0.511\right.$, $\left.\eta^{2}=0.013\right)$. At $\mathrm{T} 1$, there was a significant group difference in emotional distress due to social distancing indicating more distress in patients compared with controls $\left(F_{(1,34)}=6.62, p=0.015, \eta^{2}=0.163\right)$, no group difference was found in COVID-19 fears $\left(F_{(1,34)}=0.84, p=0.366\right.$, $\left.\eta^{2}=0.024\right)$. There were no significant time $\mathrm{x}$ group interactions in COVID-19 fears $\left(F_{(1,34)}=0.21, p=0.651\right.$, $\left.\eta^{2}=0.006\right)$ or emotional distress due to social distancing $\left(F_{(1,34)}=0.003, p=0.958, \eta^{2}=0.000\right.$; see Table 4. Age $\left(\eta^{2}=0.027\right)$, sex $\left(\eta^{2}=0.004\right)$, education $\left(\eta^{2}=0.019\right)$, and employment $\left(\eta^{2}=0.054\right)$ showed no significant effects on COVID-19 fears (all $p>0.05$ ) and on emotional distress due to social distancing (age: $\eta^{2}=0.007$; sex: $\eta^{2}=0.015$; education: $\eta^{2}=0.050$, employment: $\eta^{2}=0.028$ ). The means and standard deviations of the COVID-19 fear index and emotional distress due to social distancing index are shown in Table 4.

\section{Effects of COVID-19 fears/emotional distress to social distancing during the lockdown on psychological symptoms post-lockdown}

The regression analyses were ran with selected predictor variables (COVID-19 fears and emotional distress due to social distancing at T1) and control variables (age, sex, education, and employment) using the ENTER method, and the BSI-18 subscales as dependent variables. Results of regression analyses confirmed the hypothesis that COVID-19 fears during the lockdown were associated with psychological symptoms post-lockdown, this was bipolar-specific. In detail, in the BD group, the regression models adjusted for age, sex, education, and employment, which accounted for $59 \%$ of the variance (see Table 5), demonstrated that COVID-19 fears predicted somatization $\left(r=0.54, p=0.007 ; F_{(6,19)}=3.15, p=0.039\right.$, $\left.R^{2}=0.59\right)$. Age was identified as significant confounder in the regression model $(r=0.40, p=0.041)$. No associations between COVID-19 fears and somatization

Table 4 Results from repeated measures ANCOVAs: COVID-19 fears and emotional distress due to social distancing in patients with BD vs. healthy controls in April (T1) and May 2020 (T2)

\begin{tabular}{|c|c|c|c|c|c|c|c|c|c|c|}
\hline & \multicolumn{2}{|c|}{$\mathrm{BD}(n=20)$} & \multicolumn{2}{|c|}{ Controls $(n=20)$} & \multicolumn{6}{|c|}{ Statistics } \\
\hline & \multirow{2}{*}{$\begin{array}{l}\mathrm{T} 1 \\
M(S D)\end{array}$} & \multirow{2}{*}{$\begin{array}{l}\mathrm{T} 2 \\
M(S D)\end{array}$} & \multirow{2}{*}{$\begin{array}{l}\mathrm{T} 1 \\
M(S D)\end{array}$} & \multirow{2}{*}{$\begin{array}{l}\mathrm{T} 2 \\
M(S D)\end{array}$} & \multicolumn{2}{|c|}{ Group effect } & \multicolumn{2}{|c|}{ Time effect } & \multicolumn{2}{|c|}{$\begin{array}{l}\text { Time } x \text { group } \\
\text { interaction }\end{array}$} \\
\hline & & & & & $F$ & $p$ & $F$ & $p$ & $F$ & $p$ \\
\hline COVID-19 fears & $4.43(2.69)$ & $3.98(2.39)$ & $3.79(2.15)$ & $3.42(2.14)$ & 0.83 & 0.366 & 2.73 & 0.108 & 0.21 & 0.651 \\
\hline ED-SD & $1.56(1.16)$ & $1.13(1.04)$ & $0.78(0.51)$ & $0.79(0.96)$ & 6.62 & 0.015 & 0.442 & 0.511 & 0 & 0.958 \\
\hline
\end{tabular}

Results from repeated measures ANCOVAs controlling for age, sex, education, and employment

$B D$ bipolar disorder, $E D-S D$ emotional distress due to social distancing, $M$ mean, $S D$ standard deviation 
Table 5 Multiple linear regression of COVID-19 fears/emotional distress due to social distancing during lockdown (T1) associated with somatization at post-lockdown (T2)

\begin{tabular}{|c|c|c|c|c|c|c|c|c|c|c|}
\hline & \multicolumn{2}{|c|}{$\begin{array}{l}\text { Unstandardized } \\
\text { coefficients }\end{array}$} & \multirow{2}{*}{$\begin{array}{l}\text { Standardized } \\
\text { coefficients } \\
\beta\end{array}$} & \multirow[t]{2}{*}{$t$} & \multirow[t]{2}{*}{$p$} & \multirow[t]{2}{*}{$F(p)$} & \multirow[t]{2}{*}{$R$} & \multirow[t]{2}{*}{$R 2$} & \multirow[t]{2}{*}{$\Delta R 2$} & \multirow[t]{2}{*}{ Cohens $f$} \\
\hline & $B$ & $S E$ & & & & & & & & \\
\hline \multicolumn{11}{|l|}{ Somatization } \\
\hline \multicolumn{11}{|l|}{$\mathrm{BD}$} \\
\hline (Constant) & & & & & & $3.15(0.039 *)$ & 0.77 & 0.59 & 0.40 & 1.44 \\
\hline COVID-19 fears & 1.36 & 0.45 & 0.67 & 3.00 & $0.010^{*}$ & & & & & \\
\hline ED-SD & -0.38 & 1.04 & -0.08 & -0.37 & 0.718 & & & & & \\
\hline Age & 0.18 & .06 & 0.50 & 2.75 & $0.017^{*}$ & & & & & \\
\hline Sex & -0.60 & 2.13 & -0.06 & -0.28 & 0.783 & & & & & \\
\hline Education & 0.31 & 0.73 & 0.08 & 0.42 & 0.680 & & & & & \\
\hline Employment & -0.74 & 0.79 & -0.18 & -0.94 & 0.363 & & & & & \\
\hline \multicolumn{11}{|l|}{ Controls } \\
\hline (Constant) & & & & & & $0.38(0.878)$ & 0.38 & 0.15 & -0.24 & 0.18 \\
\hline COVID-19 fears & -0.13 & 0.25 & -0.18 & -0.53 & 0.605 & & & & & \\
\hline ED-SD & 0.82 & 1.25 & 0.27 & .66 & 0.520 & & & & & \\
\hline Age & 0.05 & 0.07 & 0.30 & .74 & 0.475 & & & & & \\
\hline Sex & -0.08 & 1.01 & -0.02 & -.08 & 0.941 & & & & & \\
\hline Education & 0.46 & 0.39 & 0.35 & 1.17 & 0.263 & & & & & \\
\hline Employment & -0.00 & 0.28 & -0.00 & -.01 & 0.994 & & & & & \\
\hline
\end{tabular}

$B D$ bipolar disorder, $E D-S D$ emotional distress due to social distancing

${ }^{*} p<0.05$ in bold; multiple linear regression results on somatization with COVID-19 fears and ED-SD as predictors corrected for age, sex, education, and employment

was observed in the control group $\left(r=0.08, p=369 ; F_{(6}\right.$, $\left.{ }_{19)}=0.38, p=0.878, R^{2}=0.15\right)$. Table 5 lists the regression coefficients and regression results on somatization in both groups. The other regression models to predict anxiety $\left(\mathrm{BD}: F_{(6,19)}=1.35, p=0.305, R^{2}=0.62\right.$; Controls: $\left.F_{(6,19)}=1.01, p=0.462, R^{2}=0.56\right)$, depression (BD: $F_{(6,19)}=1.96, p=0.146, R^{2}=0.69$; Controls: $F_{(6,19)}=2.02$, $p=0.135, R^{2}=0.70$ ), and GSI (BD: $F_{(6,19)}=1.92, p=0.152$, $R^{2}=0.69$; Controls: $\left.F_{(6,19)}=1.09, p=0.418, R^{2}=0.58\right)$ were not significant. Table 6 shows partial correlations (corrected for sex, age, education, and employment) between the regression variables. In $\mathrm{BD}$, associations between emotional distress due to social distancing at T1 and depression at T2 were observed $(r=0.63, p=0.009)$.
COVID-19 fears at T1 were related to post-lockdown somatization $(r=0.68, p=0.004)$, anxiety $(r=0.53$, $p=0.035)$, and GSI $(r=0.63, p=0.009)$. No associations between COVID-19 fears/emotional distress due to social distancing and psychological symptoms within the control group were found.

\section{Discussion}

This was the first study to survey individuals diagnosed with BD during the COVID-19 pandemic at two points of measurement-at the peak of the first Austrian lockdown in April 2020 and post-lockdown in May 2020-using a follow-up control-group design. Due to very little empirical data on the impact of the pandemic and lockdown

Table 6 Partial correlations between COVID-19 fears/emotional distress due to social distancing at T1 and BSI-18 scales at T2 in BD patients and healthy controls

\begin{tabular}{|c|c|c|c|c|c|c|c|c|}
\hline & \multicolumn{2}{|c|}{ Somatization } & \multicolumn{2}{|c|}{ Depression } & \multicolumn{2}{|c|}{ Anxiety } & \multicolumn{2}{|l|}{ GSI } \\
\hline & BD & Controls & BD & Controls & BD & Controls & $\mathrm{BD}$ & Controls \\
\hline COVID-19 fears & $0.68^{* *}$ & -0.06 & 0.43 & 0.27 & $0.53^{*}$ & -0.03 & $0.63^{* *}$ & 0.08 \\
\hline ED-SD & 0.32 & 0.12 & $0.63^{* *}$ & 0.14 & 0.13 & 0.45 & 0.43 & 0.31 \\
\hline
\end{tabular}

$B D$ bipolar disorder, $E D-S D$ emotional distress due to social distancing, GSI global symptom index

${ }^{* *} p<0.01,{ }^{*} p<0.05$ in bold letters; partial correlations were corrected for age, sex, education, and employment 
on patients with $\mathrm{BD}$, the aim of this study was to explore psychological consequences of the lockdown during the COVID-19 pandemic in this vulnerable group in order to develop possible strategies for patients to cope with the crisis.

Patients experienced social distancing during the first Austrian lockdown in April 2020 as much more burdensome than controls. They reported more emotional distress due to social distancing (including feelings of loneliness, boredom, frustration, hopelessness, and anxiety). Although the regression model revealed no effect, partial correlations in BD showed a relationship between emotional distress due to social distancing and depression scores at post-lockdown. In addition, patients with $\mathrm{BD}$ reported high values in depression, anxiety, and psychological distress (measured with GSI) during lockdown. This was in line with previous studies in samples with severe mental disorders during the COVID-19 pandemic in 2020 (Carmassi et al. 2020; González-Blanco et al. 2020; Solé et al. 2021). In comparison to healthy controls, individuals with severe mental illness reported less use of coping strategies, such as having a routine, social interactions, and a healthy lifestyle (Solé et al. 2021).

We suppose that this first lockdown in Austria may have led to high insecurity and anxiety with affective dynamics in patients with $\mathrm{BD}$ compared to controls. According to the literature, the ongoing COVID-19 pandemic is suggested to promote worries about health, personal and financial loss, uncertainties, anger, confusion, frustration, boredom, decrease in social contacts, isolation, loss in daily routine, stigma, emotional distress, and exacerbation of psychological symptoms in otherwise healthy individuals (Barzilay et al. 2020; Brooks et al. 2020; Fatke et al. 2020; Lieberman et al. 2020; PérezFuentes et al. 2020; Pfefferbaum and North 2020; Tull et al. 2020). Certain aspects of the pandemic could affect patients with BD, especially concerning the risk of relapse or disruption in biological and social rhythm (Rajkumar 2020). Studies have shown that traits related to emotional instability and anxiety are generally elevated in bipolar spectrum disorder (Evans et al. 2005; Greenwood et al. 2012; Wagner-Skacel et al. 2020). It is suggested that individuals with $\mathrm{BD}$ are less securer and more anxious than healthy people in normal situation and that this it getting more severe under extreme situation. Individuals with $\mathrm{BD}$ are prone to react to stress more extensively (Stefana et al. 2020), and this is in line with results of past epidemics and natural disasters (Esterwood and Saeed 2020) as well as recent longitudinal studies during the COVID-19 pandemic in individuals with affective disorders (Frank et al. 2020; Pan et al. 2020). The real development of COVID-19 pandemic effects on psychological conditions in patients with $\mathrm{BD}$ as a response to the crisis will be objects of further investigations.

There is a link between personality structure and affective dynamics, including depressive, anxiety, and somatization symptoms in BD. An impairment of personality functioning including difficulties in interpersonal relations as well as self-regulation in individuals with $\mathrm{BD}$ leads to more psychological distress (Wagner-Skacel et al. 2020). Additionally, we know that patients with BD usually engage in ineffective coping strategies to address stressful situations (Bender and Alloy 2011). These patients may need more stabilization in the affective regulation during the COVID-19 pandemic.

Using a $2 \times 2$ design, it was evident that patients with $\mathrm{BD}$ got closer to healthy controls from April to May in somatization, whereas healthy controls showed no significant change, rather decline, in somatization. This divided reaction of patients and controls may be caused by a rising frustration and strain over time in the control population. For people without a history of mental illness, this period of chronic emotional stress und uncertainty may have been a first-time experience. Possibly, their natural resilience may have hit its limit in May, resulting in a deterioration of their psychological condition. We suggest that patients with BD might be more familiar with such episodes of high stress. In general, we assume that healthy individuals maintain a more active social life than psychiatric individuals, wherefore changes in the social structure could strain them highly.

The decreasing trends in somatization observed in May 2020 in patients might be interpreted as depending on easing of strict lockdown. The second point of measurement was after the lockdown, along with reopening of schools, nurseries, kindergartens, restaurants/bars, hotels, recreational centers, shops, theaters, etc., when social life started to rise. We suppose that the easing of lockdown measures and thus the revival of social contact, reconstitution of psychiatric treatment, and return to "normal life" correlated with the decrease in psychological symptoms, especially somatization symptoms. Somatization is suggested as an indicator for psychological distress in the form of somatic symptoms. A recent metaanalysis revealed that medically unexplained somatic symptoms are highly prevalent among persons with BD at a rate nearly double that of the general population (Edgcomb et al. 2016). The same study group investigated predictors and outcomes of somatization in patients with BD. Somatic symptoms were independently associated with disease severity, defined as earlier age of first seeking psychiatric help and first psychiatric hospitalization, greater probability of attempting suicide, and rapid cycling course of disease (Edgcomb and Kerner 2018). Studies on somatization in patients with BD have been 
limited to anxiety subscale scores of somatization, establishing that anxiety disorders occur more frequently in persons with BD than in the general population (Pavlova et al. 2015). Research on the psychological reactions to previous epidemics suggest various vulnerability factors for anxiety and fears associated with an infectious virus, such as individual differences in intolerance of uncertainty and perceived vulnerability to disease (Esterwood and Saeed 2020; Taylor et al. 2004). In this study, COVID19 fears could predict later somatization in the BD group. Somatization refers to psychological stress caused by the perception of physical dysfunctions. The somatization items of the BSI-18 focus on body symptoms with strong autonomous mediation (Franke et al. 2017). Subjective perception, thoughts, emotions, and behaviours associated with the individual somatic status are sometimes clinically more important than a medical diagnosis. In this context, it is very important to identify anxiety and COVID-19 fears in the BD group, but also in the general population, and to find evidence-based ways of addressing these issues for future outbreaks of infection.

Although we suggest that the change in symptoms is related to the easing of restrictions, some patients with BD might adapt and perhaps benefit from the complete stop of social obligations, resulting in decreased somatization scores. Other studies found a decrease of symptoms during the course of the COVID-19 pandemic too (Orhan et al. 2020). According to our results, we see a chance for patients individually, as some might realize that others (normally nonimpaired fellow human beings) are also afraid of the consequences of the COVID-19 pandemic, e.g., fear to contract the coronavirus or to infecting others with the coronavirus.

BD has high comorbidity with obesity; metabolic disorders including diabetes mellitus, coronary heart disease, and obstructive pulmonary disease; and smoking and substance abuse (Staudt Hansen et al. 2018; McInytre et al. 2007; Vancampfort et al. 2013; Vancampfort et al. 2016; Zareifopoulos et al. 2018). These related somatic illnesses compromise immune functioning and heighten the risk for SARS-CoV-2 infection per se as well as a severe course if one is infected (Stefana et al. 2020; Yao et al. 2020). Based on this, it is surprising that our results show that patients with BD are not more afraid to contract the coronavirus than healthy controls. At both time points, patients and controls did not differ in COVID19 fears, including general concerns and fears about the coronavirus, fear of contracting the coronavirus, and fear of infecting others with the coronavirus. We suppose that patients with $\mathrm{BD}$ are not always aware of the high somatic risk factors accompanying their psychiatric disease. Thus, integrating more psychoeducational intervention programs, possibly smartphone based, related to increased somatic risk factors and SARS-CoV-2 infection would be beneficial in the treatment of BD. Otherwise, in this context it must be mentioned that lithium has shown direct antiviral effects, which might possibly protect individuals with $\mathrm{BD}$ against SARS-CoV-2 infection (Murru et al. 2020; Nowak and Walkowiak 2020). Stefana et al. (2020) indicated that social stigma flares when societies are under stress. Particularly at risk for stigmatization are vulnerable groups or those considered as "different". They suggested that, as BD is already prone to stigmatization, people with $\mathrm{BD}$ will undoubtedly take a second hit when they contract COVID-19 (Stefana et al. 2020).

\section{Limitations}

Several limitations should be considered when interpreting the current results. First, we only assessed patients with $\mathrm{BD}$ who were former study participants and who were motivated to participate in an online survey. Therefore, results may not be transferable to patients with $\mathrm{BD}$ who have not yet received therapy. We have not assessed euthymia by external rating criteria and do not know the affective status of the patients. However, affective state was monitored using self-ratings (BDI-2, ASRM). Additionally, the gender distribution in the control sample was unequal, there were more male patients than healthy controls. In addition, compared to controls, more patients were retired or in rehabilitation or had completed apprenticeship or A-Levels, which could have influenced the results. Since adverse course of COVID19 is strongly associated with age, it cannot be ruled out, that differences in symptoms may be at least partially due to the differences in age (which has been controlled in all analyses).

Second, all data were self-reported and, thus, may potentially be biased. Although we assessed COVID-19 fears and emotional responses in addition to psychological scales, it cannot be excluded that at least some symptom worsening was not directly attributable to the COVID-19 pandemic. In addition, we do not know whether the participants were being negative tested for COVID-19 or have not being tested, as this discrimination was not assessed at the beginning of the pandemic. Third, COVID-19 fears and emotional distress due to social distancing were self-conducted variables and not measured by validated, standardized questionnaires. Fourth, we only included patients with complete data at both time points, and therefore the sample was relatively small and may be too small to be of much importance. Fifth, the observation period was at the beginning of the crisis and relatively short in order to display the social effects of the pandemic such as job loss or isolation. In this respect, follow-up investigations of this study are of special interest. Sixth, we have no information on BSI-18 
scores in our sample before the outbreak of the COVID19 pandemic or prior to lockdown.

\section{Clinical implications}

There is a need for adequate and necessary attention to people with BD in the COVID-19 pandemic and to develop specific health care interventions and treatment approaches for this particular vulnerable group during the crisis. Given the high scores in scales of depression, anxiety, and somatization during the lockdown and the finding that COVID-19 fears during the lockdown predict later symptoms in individuals with $\mathrm{BD}$, interventions aimed at helping patients cope with fears and symptoms might help manage their condition. In this context, telemedicine, which obviates the risk of virus transmission inherent in face-to-face therapy, offers a great potential for delivering treatment during the COVID-19 pandemic (Torous and Wykes 2020; Wind et al. 2020; Zhou et al. 2020). Our findings show that videoconference therapy was used by a small part, only $22 \%$ of patients. However, we do not know if there was too little offer or demand. In any case, we believe that online treatment (especially during lockdown) has to be expanded significantly in the future, and it would be worthwhile to provide online or smartphone-based psychological interventions (e.g., cognitive behavioral therapy and mindfulness-based therapy) (Szentagotai and David 2009; Williams et al. 2008). In addition, patients with BD need more information about risk factors (disruption of daily rhythms, social isolation, somatic comorbidities) and their vulnerability to stress in order to protect themselves better during any time of great social disruption, whether caused by pandemic, environmental disaster, or whatnot. Specific psychosocial and psychological interventions during a pandemic could be relaxation methods and maintenance of daily rhythms. The self-awareness of patients with high somatization symptoms could be improved using strategies and skills for emotion regulation, engagement in stress-reducing activities, the regulation of relationships, and healthy lifestyle.

Much like Stefana et al. (2020) and Youngstrom et al. (2020), we are convinced that every crisis could be an opportunity by learning and rethinking and therefore gaining a more in-depth understanding of BD patients' special needs during the pandemic.

\section{Conclusion}

Our findings summarize that the COVID-19 pandemic and especially the lockdown measures greatly challenged patients with $\mathrm{BD}$. At the peak of the Austrian lockdown in April 2020, psychological symptoms were observed in patients with $\mathrm{BD}$; somatization decreased in patients from April to May 2020 along with easing of restrictions, in contrast to controls, and we conclude that this was dependent on lockdown measures. Accordingly, we want to emphasize that fears of contracting the coronavirus or fears of infecting others (so called COVID-19 fears) during the lockdown could predict later symptoms of somatization and that these results were bipolar specific. We therefore propose that patients with BD need more information about potential lockdown effects on their psychological wellbeing and about strategies for stress reduction and dealing with fears during periods of reduced psychosocial care. Patients with a higher vulnerability, including less resilience, maladaptive coping strategies, higher psychological distress, more severe course of disease, and more somatic comorbidities, have to be identified earlier and need frequent clinical contacts with a more active role of the therapist or doctor during times of crisis. Follow-up studies to estimate the long-term effects of the COVID-19 pandemic in individuals with $\mathrm{BD}$ are highly needed.

\section{Abbreviations}

SARS-CoV-2: Severe acute respiratory syndrome coronavirus-2; COVID-19: Coronavirus disease; BD: Bipolar disorder; SCID-I: Structured Clinical Interview for DSM-IV; BSI-18: Brief Symptom Inventory-18; GSI: Global severity index; BDI-2: Beck depression inventory; ASRM: Altman self rating mania scale; MANCOVA: Multivariate covariance analyses; SPSS: Statistical Package for Social Sciences; ANCOVA: Analysis of covariance.

\section{Acknowledgements}

We especially thank all study participants for their kind participation.

\section{Authors' contributions}

ND: designed the study, wrote the first and last draft, and was responsible for the study conception, coordination, and publication of data. JW: was involved in the conception of the study and writing. In addition, she supervised and guided us through the whole process of publication. MR: was involved in the conception of the study, creation of graphics, administered the online application tool LimeSurvey, and was responsible for data collection. FF: managed patient schedules and appointments and supervised the testing. ML: was involved in the conception of the study, writing, creation of graphics, and statistical data analysis. AT-B: was responsible for proofreading and revising the manuscript. $A B$ : was responsible for proofreading and revising the manuscript. $\mathrm{RQ}$ : was responsible for proofreading and revising the manuscript. SB: was responsible for proofreading and revising the manuscript. $\mathrm{CH}$ : was responsible for proofreading and revising the manuscript. AM: was responsible for proofreading and revising the manuscript. RP: supported the implementation of the survey in the online application tool LimeSurvey and was responsible for proofreading and revising the manuscript. MP: was responsible for proofreading and revising the manuscript. ER: supervised the whole study procedure and made revisions for important intellectual content. All authors read and approved the final manuscript.

\section{Funding}

The authors obtained no funding from pharmaceutical companies or other funding agencies.

\section{Availability of data and materials}

The datasets generated and or analysed during the current study are available from the corresponding author on reasonable request. 


\section{Declarations}

\section{Ethics approval and consent to participate}

The study was conducted ethically in accordance with the World Medical Association Declaration of Helsinki. All study participants gave their written informed consent, and the study protocol was approved by the local institutional committee on human research of the Medical University Graz (EK Nr: 25-335 ex 12/13).

\section{Consent for publication}

All authors consent to the publication of the manuscript in International Journal of Bipolar Disorders.

\section{Competing interests}

The authors declare that they have no competing interests.

\section{Author details}

'Department of Psychiatry and Psychotherapeutic Medicine, Medical University Graz, Auenbruggerplatz 31, Graz 8036, Austria. ${ }^{2}$ Department of Medical Psychology and Psychotherapy, Medical University of Graz, Auenbruggerplatz 3, 8036 Graz, Austria.

Received: 23 November 2020 Accepted: 24 February 2021

Published online: 01 June 2021

\section{References}

Altman EG, Hedeker D, Peterson JL, Davis JM. The Altman self-rating mania scale. Biol Psychiat. 1997;42(10):948-55. https://doi.org/10.1016/s00063223(96)00548-3.

Barzilay R, Moore TM, Greenberg DM, DiDomenico GE, Brown LA, White LK, Gur RE. Resilience, COVID-19-related stress, anxiety and depression during the pandemic in a large population enriched for healthcare providers. Transl Psychiatry. 2020;10(1):1-8.

Bender RE, Alloy LB. Life stress and kindling in bipolar disorder: review of the evidence and integration with emerging biopsychosocial theories. Clin Psychol Rev. 2011;31(3):383-98.

Bengesser S, Reininghaus E. Polygenic risk scores and bipolar disorder. J Psychiatry Brain Sci. 2018;3(6):1-11.

Brietzke E, Mansur RB, Soczynska J, Powell AM, McIntyre RS. A theoretical framework informing research about the role of stress in the pathophysiology of bipolar disorder. Prog Neuropsychopharmacol Biol Psychiatry. 2012:39(1):1-8.

Brooks SK, Webster RK, Smith LE, Woodland L, Wessely S, Greenberg N, Rubin GJ. The psychological impact of quarantine and how to reduce it: rapid review of the evidence. Lancet. 2020;395:912-20. https://doi.org/10.1016/ s0140-6736(20)30460-8.

Carmassi C, Bertelloni CA, Dell'Oste V, Barberi FM, Maglio A, Buccianelli B, Cordone A, Dell'Osso L. Tele-psychiatry assessment of post-traumatic stress symptoms in 100 patients with bipolar disorder during the COVID19 Pandemic social-distancing measures in Italy. Front Psychiatry. 2020. https://doi.org/10.3389/fpsyt.2020.580736.

Chang KC, Hou WL, Pakpour AH, Lin CY, Griffiths MD. Psychometric testing of three COVID-19-related scales among people with mental illness. Int J Ment Heal Addict. 2020. https://doi.org/10.1007/s11469-020-00361-6.

Cohen JE. Statistical power analysis for the behavioral sciences. Hillsdale: Lawrence Erlbaum Associates Inc; 1988.

Costa M, Pavlo A, Reis G, Ponte K, Davidson L. COVID-19 concerns among persons with mental illness. Psychiatr Serv. 2020;71(11):1188-90. https:// doi.org/10.1176/APPI.PS.202000245.

Courtet P, Olié E, Debien C, Vaiva G. Keep socially (but not physically) connected and carry on: preventing suicide in the age of COVID-19. J Clin Psychiatr. 2020;81(3):1-3.

Dalkner N, Bengesser S, Birner A, Rieger A, Seebauer J, Platzer M, Hamm C, Maget A, Queissner R, Pilz R, Fellendorf F, Reininghaus B, Strassnig M, Kapfhammer HP, Reininghaus EZ. Body mass index predicts decline in executive function in bipolar disorder: preliminary data of a 12-month follow-up study. Neuropsychobiology. 2020;80:1-11.
Derogatis $L R$, Fitzpatrick M. The SCL-90-R, the brief symptom inventory (BSI), and the BSI-18. In: Maruish ME, editor. The use of psychological testing for treatment planning and outcomes assessment: instruments for adults. Hillsdale: Lawrence Erlbaum Associates Publishers; 2004. p. 1-41.

Derogatis LR, Unger R. Symptom checklist-90-revised. In: Weiner IB, Craighead WE, editors. The Corsini encyclopedia of psychology. Hoboken: Wiley; 2010. p. 1-2. https://doi.org/10.1002/9780470479216.corpsy0970.

Dsouza DD, Quadros S, Hyderabadwala ZJ, Mamun MA. Aggregated COVID-19 suicide incidences in India: fear of COVID-19 infection is the prominent causative factor. Psychiatr Res. 2020;290:e113145.

Edgcomb JB, Kerner B. Predictors and outcomes of somatization in bipolar I disorder: a latent class mixture modeling approach. J Affect Disord. 2018;227:681-7. https://doi.org/10.1016/j.jad.2017.11.083.

Edgcomb JB, Tseng CH, Kerner B. Medically unexplained somatic symptoms and bipolar spectrum disorders: a systematic review and meta-analysis. J Affect Disord. 2016;204:205-13.

Esterwood E, Saeed SA. Past epidemics, natural disasters, COVID19, and mental health: learning from history as we deal with the present and prepare for the future. Psychiatr Q. 2020. https://doi.org/10.1007/ s11126-020-09808-4.

Evans L, Akiskal HS, Keck PE Jr, McElroy SL, Sadovnick AD, Remick RA, Kelsoe $J$ R. Familiality of temperament in bipolar disorder: support for a genetic spectrum. J Affect Disord. 2005;85(1-2):153-68. https://doi.org/10.1016/j. jad.2003.10.015.

Fatke B, Hölzle P, Frank A, Förstl H. Psychische probleme in der pandemie-beobachtungen während der COVID-19-krise. DMW. 2020;145(10):675-81. https://doi.org/10.1055/a-1147-2889.

Frank A, Fatke B, FrankW, Förstl H, Hölzle P. Depression, dependence and prices of the COVID-19-Crisis. Brain Behav Immun. 2020. https://doi.org/10. 1016/j.bbi.2020.04.068.

Franke GH, Jaeger S, Glaesmer H, Barkmann C, Petrowski K, Braehler E. Psychometric analysis of the brief symptom inventory 18 (BSI-18) in a representative German sample. BMC Med Res Methodol. 2017;17(1):14.

González-Blanco L, Dal Santo F, García-Álvarez L, de la Fuente-Tomás L, Lacasa CM, Paniagua G, et al. COVID-19 lockdown in people with severe mental disorders in Spain: do they have a specific psychological reaction compared with other mental disorders and healthy controls? Schizophr Res. 2020;223:192-8. https://doi.org/10.1016/j.schres.2020.07.01.

Greenwood TA, Akiskal HS, Akiskal KK, Study BG, Kelsoe JR. Genome-wide association study of temperament in bipolar disorder reveals significant associations with three novel Loci. Biol Psychiat. 2012;72(4):303-10. https://doi.org/10.1016/j.biopsych.2012.01.018.

Guan WJ, Ni ZY, Hu Y, Liang WH, Ou CQ, He JXB, et al. Clinical characteristics of coronavirus disease 2019 in China. N Engl J Med. 2020;382(18):1708-20. https://doi.org/10.1056/nejmoa2002032.

Hansen PS, Laursen MF, Grøntved S, StraszekLicht SPVRW, Nielsen RE. Increasing mortality gap for patients diagnosed with bipolar disorder-a nationwide study with 20 years of follow-up. Bipolar Disord. 2019;21(3):270-5. https://doi.org/10.1111/bdi.12684.

Hao F, Tan W, Jiang L, Zhang L, Zhao X. Do psychiatric patients experience more psychiatric symptoms during COVID-19 pandemic and lockdown? A case-control study with service and research implications for immunopsychiatry. Brain Behav Immun. 2020. https://doi.org/10.1016/j.bbi. 2020.04.069.

Ho CS, Chee CY, Ho RC. Mental health strategies to combat the psychological impact of COVID-19 beyond paranoia and panic. Ann Acad Med Singap. 2020:49(1):1-3.

Holmes EA, O'Connor RC, Perry VH, Tracey I, Wessely S, Arseneault L, Ford T. Multidisciplinary research priorities for the COVID-19 pandemic: a call for action for mental health science. The Lancet Psychiatry. 2020;7:547-60. https://doi.org/10.1016/s2215-0366(20)30168-1.

lasevoli F, Fornaro M, D'Urso G, Galletta D, Casella C, Paternoster M, et al. Psychological distress in patients with serious mental illness during the COVID-19 outbreak and one-month mass quarantine in Italy. Psychol Med. 2020. https://doi.org/10.1017/\$0033291720001841.

Johns Hopkins University. (2020). COVID-19 dashboard by the Center for Systems Science and Engineering (CSSE) at Johns Hopkins University (JHU). https://coronavirus.jhu.edu/map.html. Accessed 28 Sept 2020.

Klomek AB. Suicide prevention during the COVID-19 outbreak. The Lancet Psychiatry. 2020;7(5):390. 
Kühner C, Bürger C, Keller F, Hautzinger M. Reliability and validity of the revised beck depression inventory (BDI-II). Results from German samples. Der Nervenarzt. 2007;78(6):651-6.

Lieberman L, Petrey K, Shankman SA, Phan KL, Gorka SM. Heightened reactivity to uncertain threat as a neurobehavioral marker of suicidal ideation in individuals with depression and anxiety. Int J Psychophysiol. 2020;155:99-104. https://doi.org/10.1016/j.jpsycho.2020.06.003.

Malkoff-Schwartz S, Frank E, Anderson BP, Hlastala SA, Luther JF, Sherrill JT, et al. Social rhythm disruption and stressful life events in the onset of bipolar and unipolar episodes. Psychol Med. 2000;30(5):1005-16.

Mamun MA, Griffiths MD. First COVID-19 suicide case in Bangladesh due to fear of COVID-19 and xenophobia: possible suicide prevention strategies. Asian J Psychiatr. 2020;51:102073.

McIntyre RS, Soczynska JK, Beyer JL, Woldeyohannes HO, Law CW, Miranda A, et al. Medical comorbidity in bipolar disorder: reprioritizing unmet needs. Curr Opin Psychiatry. 2007;20(4):406-16.

Murru A, Manchia M, HajekT, Nielsen RE, Rybakowski JK, Sani G, et al. Lithium's antiviral effects: a potential drug for CoViD-19 disease. Int J Bipolar Disord. 2020:8:1-9.

Muruganandam P, Neelamegam S, Menon V, Alexander J, Chaturvedi SK. COVID19 and severe mental illness: impact on patients and its relation with their awareness about COVID-19. Psychiatry Res. 2020;291:113265. https://doi. org/10.1016/j.psychres.2020.113265.

Nowak JK, Walkowiak J. Lithium and coronaviral infections. A scoping review. F1000Research. 2020. https://doi.org/10.12688/f1000research.22299.2.

Nussmayr K. 15 Grafiken, die die Verbreitung des Coronavirus in Österreich und der Welt erklären. Die Presse. 2020. https://www.diepresse.com/5785804/ 15-grafiken-die-die-verbreitung-des-coronavirus-in-osterreich-und-derwelt-erklaren. Accessed 29 Sept 2020.

Orhan M, Korten N, Paans N, de Walle B, Kupka R, van Oppen P, Kok A, Sonnenberg C, Schouws S, Dols A. Psychiatric symptoms during the COVID-19 outbreak in older adults with bipolar disorder. Int J Geriatr Psychiatry. 2020. https://doi.org/10.1002/gps.548910.1002/gps.5489.

Pan KY, Kok AA, Eikelenboom M, Horsfall M, Jörg F, Luteijn RA, et al. The mental health impact of the COVID-19 pandemic on people with and without depressive, anxiety, or obsessive-compulsive disorders: a longitudinal study of three Dutch case-control cohorts. The Lancet Psychiatry. 2020;0366:1-9. https://doi.org/10.1016/S2215-0366(20)30491-0.

Pavlova B, Perlis RH, Alda M, Uher R. Lifetime prevalence of anxiety disorders in people with bipolar disorder: a systematic review and meta-analysis. The Lancet Psychiatry. 2015;2(8):710-7. https://doi.org/10.1016/s2215-0366(15) 00112-1.

Pérez-Fuentes MDC, Jurado MDMM, Martínez ÁM, Linares JJG. Threat of COVID19 and emotional state during quarantine: positive and negative affect as mediators in a cross-sectional study of the Spanish population. PLoS ONE. 2020;15(6):e0235305. https://doi.org/10.1371/journal.pone.0235305.

Pfefferbaum B, North CS. Mental health and the Covid-19 pandemic. N Engl J Med. 2020;383:510-2. https://doi.org/10.1056/nejmp2008017.

Rajkumar RP. COVID-19 and mental health: a review of the existing literature. Asian J Psychiatr. 2020;52:102066. https://doi.org/10.1016/j.ajp.2020.102066.

Riblet NB, Stevens SP, Shiner B, Cornelius S, Forehand J, Scott RC, Watts BV. Longitudinal examination of COVID-19 public health measures on mental health for rural patients with serious mental illness. Mil Med. 2020. https://doi.org/ 10.1093/milmed/usaa559.

Rossi R, Socci V, Talevi D, Mensi S, Niolu C, Pacitti F, et al. COVID-19 pandemic and lockdown measures impact on mental health among the general population in Italy. Front Psychiatry. 2020;11:790. https://doi.org/10.3389/fpsyt. 2020.00790.

Semo BW, Frissa SM. The mental health impact of the COVID-19 pandemic: implications for sub-Saharan Africa. Psychol Res Behav Manag. 2020;13:713.

Sher L. The impact of the COVID-19 pandemic on suicide rates. QJM. 2020;10:707-12

Solé B, Verdolini N, Amoretti S, Montejo L, Rosa AR, Hogg B, et al. Effects of the COVID-19 pandemic and lockdown in Spain: comparison between community controls and patients with a psychiatric disorder. Preliminary results from the BRIS-MHC STUDY. J Affect Disord. 2021;281:13-23. https://doi.org/ 10.1016/j.jad.2020.11.099.

Stefana A, Youngstrom EA, Jun C, Hinshaw S, Maxwell V, Michalak E, Vieta E. The COVID-19 pandemic is a crisis and opportunity for bipolar disorder. Bipolar Disord. 2020;22:641-3. https://doi.org/10.1111/bdi.12949.
Szentagotai A, David D. The efficacy of cognitive-behavioral therapy in bipolar disorder: a quantitative meta-analysis. J Clin Psychiatry. 2009;71 (1):66-72.

Taylor SE, Lerner JS, Sage RM, Lehman BJ, Seeman TE. Early environment, emotions, responses to stress, and health. J Pers. 2004;72(6):1365-94. https://doi. org/10.1111/j.1467-6494.2004.00300.x.

Torous J, Wykes T. Opportunities from the coronavirus disease 2019 pandemic for transforming psychiatric care with telehealth. JAMA Psychiat. 2020;11:e1-2. https://doi.org/10.1001/jamapsychiatry.2020.1640.

Tull MT, Edmonds KA, Scamaldo K, Richmond JR, Rose JP, Gratz KL. Psychological outcomes associated with stay-at-home orders and the perceived impact of COVID-19 on daily life. Psychiatry Res. 2020;289:1-6.

Van Rheenen TE, Meyer D, Neill E, Phillipou A, Tan EJ, Toh WL, Rossell SL. Mental health status of individuals with a mood-disorder during the COVID-19 pandemic in Australia: initial results from the COLLATE project. J Affect Disord. 2020;275:69-77. https://doi.org/10.1016/j.jad.2020.06.037.

Vancampfort D, Vansteelandt K, Correll CU, Mitchell AJ, De Herdt A, Sienaert P, et al. Metabolic syndrome and metabolic abnormalities in bipolar disorder: a meta-analysis of prevalence rates and moderators. Am J Psychiatry. 2013;170(3):265-74. https://doi.org/10.1176/appi.ajp.2012.12050620.

Vancampfort D, Correll CU, Galling B, Probst M, De Hert M, Ward PB, et al. Diabetes mellitus in people with schizophrenia, bipolar disorder and major depressive disorder: a systematic review and large scale meta-analysis. World Psychiatry. 2016;15(2):166-74. https://doi.org/10.1002/wps.20309.

Vieta E, Berk M, Birmaher B, Grande I. Bipolar disorder: defining symptoms and comorbidities-authors' reply. The Lancet. 2016;388(10047):869-70. https:// doi.org/10.1016/S0140-6736(16)30966-7.

Wagner-Skacel J, Bengesser S, Dalkner N, MörkI S, Painold A, Hamm C, et al. Personality structure and attachment in bipolar disorder. Front Psych. 2020;11:410. https://doi.org/10.3389/fpsyt.2020.00410.

Weiss RB, Stange JP, Boland EM, Black SK, LaBelle DR, Abramson LY, Alloy LB. Kindling of life stress in bipolar disorder: comparison of sensitization and autonomy models. J Abnorm Psychol. 2015;124(1):4.

Williams JMG, Alatiq Y, Crane C, Barnhofer T, Fennell MJ, Duggan DS, et al. Mindfulness-based cognitive therapy (MBCT) in bipolar disorder: preliminary evaluation of immediate effects on between-episode functioning. J Affect Disord. 2008;107(1-3):275-9.

Wind TR, Rijkeboer M, Andersson G, Riper H. The COVID-19 pandemic: the 'black swan'for mental health care and a turning point for e-health. Internet Interv. 2020;100317:1-2. https://doi.org/10.1016/j.invent.2020.100317.

Wu W, Zhang Y, Wang P, Zhang L, Wang G, Lei G, et al. Psychological stress of medical staffs during outbreak of COVID-19 and adjustment strategy. J Med Virol. 2020;92:1962-70.

Yao H, Chen JH, Xu YF. Patients with mental health disorders in the COVID-19 epidemic. The Lancet Psychiatry. 2020;7(4):e21. https://doi.org/10.1016/ s2215-0366(20)30090-0.

Youngstrom EA, Hinshaw SP, Stefana A, Chen J, Michael K, Van Meter A, et al. Working with bipolar disorder during the COVID-19 pandemic: both crisis and opportunity. Wiki J Med. 2020;7(1):4. https://doi.org/10.31234/osf.io/ wg4bj.

Zandifar A, Badrfam R. Iranian mental health during the COVID-19 epidemic. Asian J Psychiatr. 2020;51:101990. https://doi.org/10.1016/j.ajp.2020.101990.

Zareifopoulos N, Bellou A, Spiropoulou A, Spiropoulos K. Prevalence of comorbid chronic obstructive pulmonary disease in individuals suffering from schizophrenia and bipolar disorder: a systematic review. COPD. 2018;15(6):612-20. https://doi.org/10.1080/15412555.2019.1572730.

Zhou X, Snoswell CL, Harding LE, Bambling M, Edirippulige S, Bai X, et al. The role of telehealth in reducing the mental health burden from COVID-19. Telemed e-Health. 2020;26(4):377-9. https://doi.org/10.1089/tmj.2020.0068.

Zou S, Liu ZH, Yan X, Wang H, LiY, Xu X, et al. Prevalence and correlates of fatigue and its association with quality of life among clinically stable older psychiatric patients during the COVID-19 outbreak: a cross-sectional study. Glob Health. 2020;16(1):1-7.

\section{Publisher's Note}

Springer Nature remains neutral with regard to jurisdictional claims in published maps and institutional affiliations. 